\title{
Erratum to: Acaricidal effect and histological damage induced by Bacillus thuringiensis protein extracts on the mite Psoroptes cuniculi
}

\author{
Emmanuel Dunstand-Guzmán ${ }^{1}$, Guadalupe Peña-Chora², Claudia Hallal-Calleros ${ }^{1}$, Mario Pérez-Martínez ${ }^{3}$, \\ Víctor Manuel Hernández-Velazquez ${ }^{4}$, Jorge Morales-Montor ${ }^{5}$ and Fernando Iván Flores-Pérez ${ }^{1 *}$
}

The original version of this article [1] unfortunately contained mistakes. Panel headings in Figs. 3, 4 and 5 (Figs. 1, 2 and 3 here) were included incorrectly.

The first column in Fig. 3 (Fig. 1) should have been labelled 'Control' the third column 'Ivermectin'. The first row should be labelled 'Intestine' the second 'Ventricle'.

The first row in Fig. 4 (Fig. 2) should have been labelled 'Control' the second row should be "GP-132 BT", and the third row 'Ivermectin'. Panel 'b2' should have been labelled 'b1'.

The first column in Fig. 5 (Fig. 3) should have been labelled 'Control', the third column 'Ivermectin'.

The figures are included correctly below and have been updated in the original publication.

\begin{abstract}
Author details
${ }^{1}$ Facultad de Ciencias Agropecuarias, Universidad Autónoma del Estado de Morelos, Av. Universidad 1001, Col. Chamilpa, Cuernavaca 62209, Morelos, Mexico. ${ }^{2}$ Centro de Investigaciones Biológicas, Universidad Autónoma del Estado de Morelos, Av. Universidad 1001, Col. Chamilpa, Cuernavaca 62209, Morelos, Mexico. ${ }^{3}$ Facultad de Medicina Veterinaria y Zootecnia, Universidad Nacional Autónoma de México, Av. Universidad 3000, Col. Copilco, Ciudad de México 04510, Mexico. ${ }^{4}$ Centro de Investigación en Biotecnología, Universidad Autónoma del Estado de Morelos, Av. Universidad 1001, Col. Chamilpa, Cuernavaca 62209, Morelos, Mexico. ${ }^{5}$ Departamento de Inmunología, Instituto de Investigaciones Biomédicas, Universidad Nacional Autónoma de México, AP 70228, México, DF 04510, Mexico.
\end{abstract}

Received: 20 July 2015 Accepted: 20 July 2015

Published online: 18 August 2015

\section{Reference}

1. Dunstand-Guzmán E, Peña-Chora G, Hallal-Calleros C, Pérez-Martínez M, Hernández-Velazquez V, Morales-Montor J, et al. Acaricidal effect and histological damage induced by Bacillus thuringiensis protein extracts on the mite Psoroptes cuniculi. Parasit Vectors. 2015;8:285.

\footnotetext{
*Correspondence: ivan.flores@uaem.mx

${ }^{1}$ Facultad de Ciencias Agropecuarias, Universidad Autónoma del Estado de Morelos, Av. Universidad 1001, Col. Chamilpa, Cuernavaca 62209, Morelos,
} Mexico

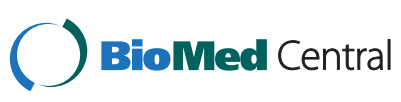

() 2015 Dunstand-Guzmán et al. This is an Open Access article distributed under the terms of the Creative Commons Attribution License (http://creativecommons.org/licenses/by/4.0), which permits unrestricted use, distribution, and reproduction in any medium, provided the original work is properly credited. The Creative Commons Public Domain Dedication waiver (http://creativecommons.org/publicdomain/zero/1.0/) applies to the data made available in this article, unless otherwise stated.
Submit your next manuscript to BioMed Central and take full advantage of:

- Convenient online submission

- Thorough peer review

- No space constraints or color figure charges

- Immediate publication on acceptance

- Inclusion in PubMed, CAS, Scopus and Google Scholar

- Research which is freely available for redistribution

Submit your manuscript at

www.biomedcentral.com/submit 

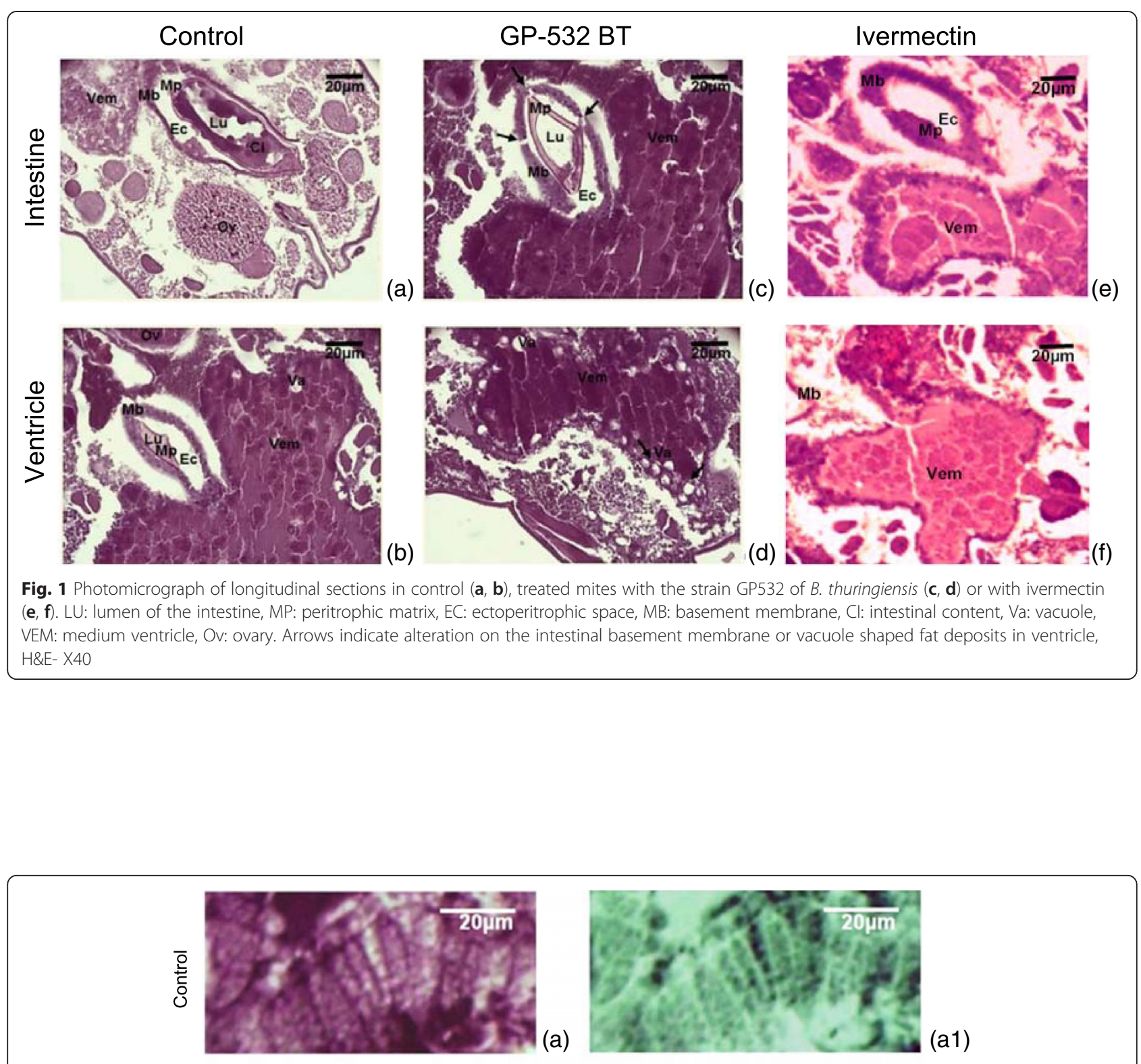

(a1)
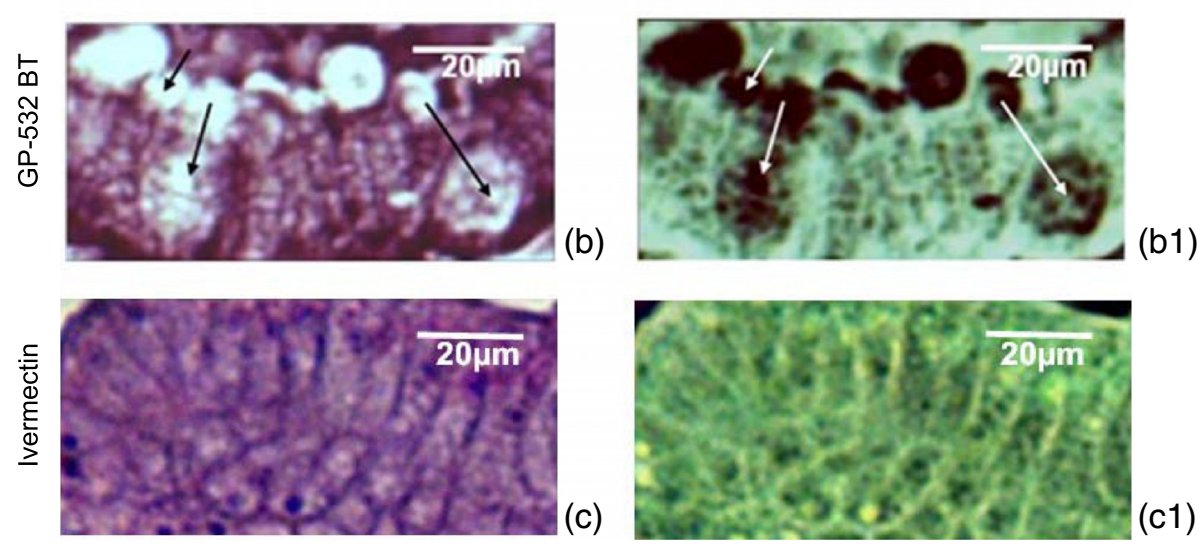

Fig. 2 Representative image of the structure of the columnar cells in the mite $P$. cuniculi without treatment (a) or after treatment with the strain GP532 of B. thuringiensis (b) or ivermectin c, and their respective images through the relief filter (a1, b1, c1). Arrows indicate presence of dilated intercellular spaces of the columnar epithelium regarding the peritrophic matrix. Bar $=20 \mu \mathrm{m}$ 


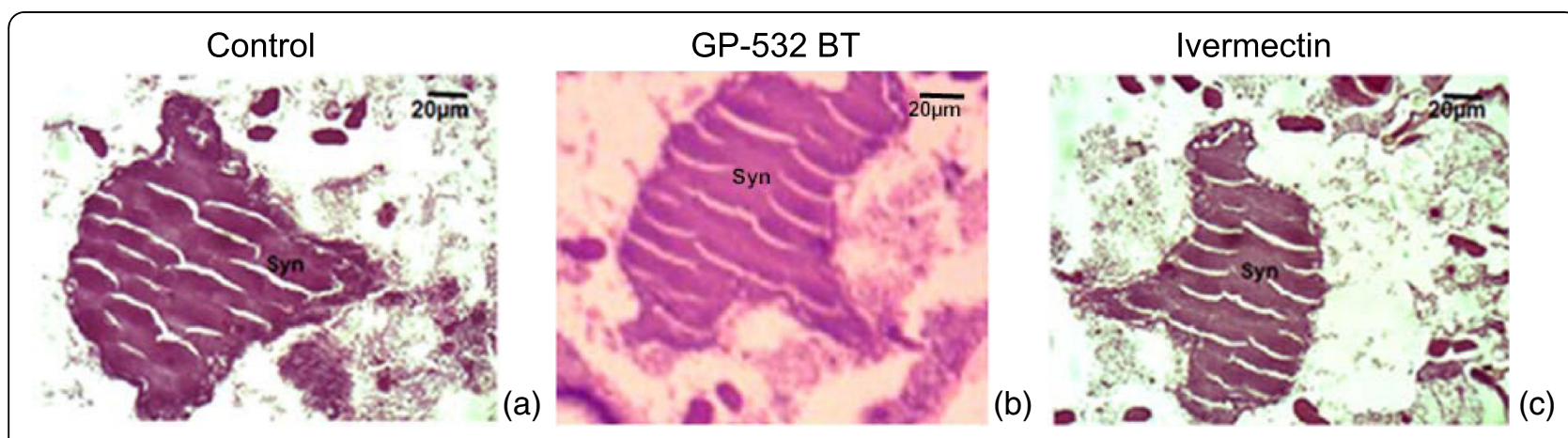

Fig. 3 Photomicrograph of longitudinal sections in nervous system of control mites (a) or treated with the strain GP532 of B. thuringiensis (b) or ivermectin (c). Syn: Synganglion 